\title{
Androgen receptor regulation of the seladin-1/DHCR24 gene: altered expression in prostate cancer
}

\author{
Lorella Bonaccorsi ${ }^{1,7}$, Paola Luciani ${ }^{2,7}$, Gabriella Nesi $^{3}$, Edoardo Mannucci ${ }^{4}$, Cristiana Deledda ${ }^{2}$, Francesca Dichiara ${ }^{2}$, \\ Milena Paglierani ${ }^{3}$, Fabiana Rosati ${ }^{2}$, Lorenzo Masieri ${ }^{5}$, Sergio Serni ${ }^{5}$, Marco Carini ${ }^{5}$, Laura Proietti-Pannunzi ${ }^{6}$, \\ Salvatore Monti ${ }^{6}$, Gianni Forti ${ }^{1,2}$, Giovanna Danza ${ }^{2}$, Mario Serio ${ }^{2}$ and Alessandro Peri ${ }^{2}$
}

Prostate cancer (CaP) represents a major leading cause of morbidity and mortality in the Western world. Elevated cholesterol levels, resulting from altered cholesterol metabolism, have been found in CaP cells. Seladin-1 (SELective Alzheimer Disease INdicator-1)/DHCR24 is a recently described gene involved in cholesterol biosynthesis. Here, we demonstrated the androgen regulation of seladin-1/DHCR24 expression, due to the presence of androgen responsive element sequences in its promoter region. In metastatic androgen receptor-negative CaP cells seladin-1/DHCR24 expression and cholesterol amount were reduced compared to androgen receptor-positive cells. In tumor samples from 61 patients who underwent radical prostatectomy the expression of seladin-1/DHCR24 was significantly higher with respect to normal tissues. In addition, in cancer tissues mRNA levels were positively related to T stage. In tumor specimens from 23 patients who received androgen ablation treatment for 3 months before surgery seladin-1/DHCR24 expression was significantly lower with respect to patients treated by surgery only. In conclusion, our study demonstrated for the first time the androgen regulation of the seladin-1/DHCR24 gene and the presence of a higher level of expression in CaP tissues, compared to the normal prostate. These findings, together with the results previously obtained in metastatic disease, suggest an involvement of this gene in CaP.

Laboratory Investigation (2008) 88, 1049-1056; doi:10.1038/labinvest.2008.80; published online 1 September 2008

KEYWORDS: androgen responsive element; cholesterol; prostate cancer; seladin-1/DHCR24

Prostate cancer $(\mathrm{CaP})$ is a major leading cause of male cancer related death, second only to lung cancer, and represents $10 \%$ of all cancer deaths in men in the United States. In this country, one in six men will be diagnosed with $\mathrm{CaP}$ during their life time. ${ }^{1}$ In the past years there has been a strong increase in the proportion of patients diagnosed with $\mathrm{CaP}$ confined to the gland, as a consequence of widespread detection strategies based on the measurements of the level of prostate-specific antigen (PSA) in the blood. ${ }^{2}$ After radical prostatectomy, the increase of serum PSA is a marker of biochemical recurrence. As PSA is an androgen-regulated gene, biochemical recurrence of CaP by PSA relapse is in itself evidence of the androgen receptor (AR) dependence of the tumor. The key role of androgen signalling has been further highlighted by the chromosomal rearrangements recently identified in the majority of $\mathrm{CaP}^{3}$ Following these unbalanced rearrangements, the coding sequences of ERG, a member of ETS transcription factors family, are leaded under the regulatory sequences of the androgen-regulated gene TMPRSS2. ${ }^{3}$ The newly formed fusion gene thus becomes a candidate oncogene in $\mathrm{CaP}^{4}$ Recently, Hendriksen et $a l^{5}$ observed that in primary $\mathrm{CaP}$ specimens reduced expression levels of AR-related genes, including seladin-1 (for SELective Alzheimer Disease INdicator-1; also known as DHCR24 for 3 - $\beta$-hydroxysterol- $\delta$-24-reductase), correlated with an increased risk to develop metastases. DHCR24 is the enzyme that converts desmosterol into cholesterol. ${ }^{6}$ The role of seladin-1/DHCR24 in cholesterol biosynthesis has been

\footnotetext{
'Unit of Andrology, Department of Clinical Physiopathology, Center for Transfer, High Education and Technology (DENOThe), University of Florence, Florence, Italy; ${ }^{2}$ Unit of Endocrinology, Department of Clinical Physiopathology, Center for Transfer, High Education and Technology (DENOThe), University of Florence, Florence, Italy; ${ }^{3}$ Department of Human Pathology and Oncology, University of Florence, Florence, Italy; ${ }^{4}$ Geriatric Cardiology, Careggi University Hospital, Florence, Italy; ${ }^{5}$ Unit of Urology, Department of Critical Care Medicine and Surgery, University of Florence, Florence, Italy and ${ }^{6}$ Unit of Endocrinology, Sant'Andrea Hospital UOC, II University of Rome 'La Sapienza', Rome, Italy

Correspondence: Professor A Peri, MD, PhD, Unit of Endocrinology, Department of Clinical Physiopathology, Center for Transfer, High Education and Technology (DENOThe), University of Florence, Viale Pieraccini, 6, 50139 Florence, Italy.

E-mail: a.peri@dfc.unifi.it

${ }^{7}$ These authors contributed equally to this work.

Received 13 February 2008; revised 03 June 2008; accepted 11 June 2008
} 
recently linked to membrane cholesterol content and lipid rafts regulation. ${ }^{7}$ Lipid rafts are cholesterol-rich membrane compartments, that are able to selectively retain or exclude specific cohorts of proteins affecting intracellular signalling. Elevated cholesterol levels in $\mathrm{CaP}$ cell membranes have been linked with lipid rafts deregulation and consequent activation of signalling pathways that promote growth advantage. ${ }^{8}$ An additional property of seladin-1/DHCR24 is to inhibit the activation of caspase 3, a key modulator of apoptosis. ${ }^{9}$ However, another study indicated that this multifaced protein may have a more complex role in cell apoptosis. In fact, following oncogenic and oxidative stress, seladin-1/DHCR24 was found to bind P53 N-terminal domain and to displace E3 ubiquitin ligase $\mathrm{Mdm} 2$ from P53, thus resulting in P53 accumulation. ${ }^{10}$ Altered levels of seladin-1/DHCR24 expression have been associated to a more aggressive phenotype in melanomas, ${ }^{11}$ adrenal cortex tumors ${ }^{12}$ and pituitary adenomas. ${ }^{13}$ It has been hypothesized that the androgen-responsiveness of seladin-1/DHCR24 may be due to the presence of an androgen responsive element (ARE) found in the gene promoter region, ${ }^{14}$ even though its functional activity has never been proven. In the present study we first focused on the functional activity of seladin-1/DHCR24 ARE sequences by a luciferase reporter gene assay in order to prove that these sequences mediate the androgen-responsiveness of seladin-1/ DHCR24 in prostate cells. With regard to this issue, we then investigated the expression levels of this gene and the modifications of cell cholesterol content in AR-positive and ARnegative $\mathrm{CaP}$ cell lines. Finally, we determined the amount of seladin-1/DHCR24 mRNA and protein in tumor prostate specimens from radical prostatectomy in order to evaluate whether the expression of this gene may be implicated in CaP.

\section{MATERIALS AND METHODS}

\section{Specimens, Clinical Data and Prostate Cancer Cell Lines}

A total of $61 \mathrm{CaP}$ samples were obtained from 61 patients undergoing radical prostatectomy at the University of Florence and University of Rome 'La Sapienza' after informed consent of patients and prior institutional review boards approval. After complete staging procedure the option of radical prostatectomy was offered to all patients who met universally accepted criteria. ${ }^{15}$ Biochemical recurrence was defined as a PSA level $>0.5 \mathrm{ng} / \mathrm{ml}$ at any follow-up visit. Fresh CaP tissue was harvested according to Bova et al. ${ }^{16}$ Frozen sections were used to confirm that the tumor samples contained at least $70 \%$ of cancer cells. For control, we used normal prostate tissue excised from the same prostates. Histologic review of radical prostatectomy specimens was performed by the same pathologist. Pathologic stage was assigned according to the 2002 TNM classification. ${ }^{17}$ Tumor grade was assessed by the Gleason system on surgical samples. Fresh prostate tissue was harvested according to standardized procedures. The frozen tissue blocks were sectioned and collected for RNA extraction. Additional 24 $\mathrm{CaP}$ samples from patients, who received androgen ablation treatment before surgery based on the decision of the urologist, were included in the study in order to determine the expression of the seladin-1/DHCR24 gene.

In addition, $\mathrm{CaP}$ cell lines were included in the study. We performed analyses by using the AR-negative cell lines PC3, DU145 and the AR-positive cell lines LnCap, DU145-AR ${ }^{18}$ and PC3-AR ${ }^{19}$ both stably transfected with hAR.

\section{Quantitative Real-Time RT-PCR for Seladin-1/DHCR24}

Total RNA was isolated from paired tumor and normal tissues with Trizol reagent (Invitrogen, Carlsbad, CA, USA) according to the manufacturer's instructions. Total RNA was also obtained from the $\mathrm{CaP}$ cell lines. The concentration was determined spectrophotometrically with Nanodrop ${ }^{\circledR}$ ND1000. Total RNA $(0.5 \mu \mathrm{g})$ was reverse transcribed into cDNA by using TaqMan reverse transcription reagents with random examers (Applied Biosystems Inc., Foster City, CA, USA). The profile of the reverse transcription reaction was $10 \mathrm{~min}$ at $25^{\circ} \mathrm{C}, 30 \mathrm{~min}$ at $48^{\circ} \mathrm{C}$ and $5 \mathrm{~min}$ at $95^{\circ} \mathrm{C}$. The absolute quantification of seladin-1/DHCR24 RNA was performed by real-time RT-PCR. TaqMan primers, probe and thermal cycling conditions were as previously described. ${ }^{12}$ Primers and probe for PSA (Unigene ID Hs.171995) were Assay-OnDemand gene expression products (assay no. Hs00426859_g1) purchased from Applied Biosystems. The human GAPDH (Unigene ID Hs.479728) mRNA was chosen as the reference gene (Hs02758991_g1; Applied Biosystems). PCR mixture (25 $\mu$ l final volume) consisted of $1 \times$ final concentration of Assay-On-Demand mix, $1 \times$ final concentration of Universal PCR Master Mix (Applied Biosystems) and 20 ng cDNA. Each measurement was carried out in triplicate. The mRNA quantitation was based on the comparative $\mathrm{Ct}$ method according to the manufacturer's instructions (Applied Biosystems) and data were normalized to GAPDH expression.

\section{Plasmids and Transient Transfection Assays}

The human seladin-1/DHCR24 promoter sequence from -4384 to -2892 containing the ARE element was amplified by PCR from human genomic DNA using the left primer with the KpnI restriction enzyme site and the right primer with the NheI site: $5^{\prime}$-ggtacctcttggtcaatctgcattcg- $3^{\prime}$ and $5^{\prime}$-gctagcctggagtcaaagcagcttcc- $3^{\prime}$. The 1483 bp PCR product was subcloned into the pCRII TOPO vector (Invitrogen, SRL, Milan, Italy), sequenced and cut out by digestion with $K p n \mathrm{I}$ and NheI. ${ }^{20}$ The excided sequence was successively cloned into the KpnI/NheI site of the tataluciferase vector ${ }^{21}$ containing a minimal TATA promoter upstream of a luciferase reporter gene, to obtain selaprom-tataluc plasmid. $\mathrm{CHO}$ cell line (American Type Tissue Collection, Manassas, VA, USA) and human benign prostate hyperplasia (BPH) cells $^{22}$ were plated in 24-well plates and were transfected with $400 \mathrm{ng}$ of reporter (selaprom-tataluc plasmid), $80 \mathrm{ng}$ of AR (pSVAR0 expression plasmid), ${ }^{23}$ and $10 \mathrm{ng}$ of the pGL 4.75 Renilla luciferase normalization vector (Promega Corp., Madison, WI, USA) by using Lipofectamin 2000 
(Invitrogen). Cells were treated with ethanol vehicle or R1881 (10 nM, 24h) (NEN; PerkinElmer, Waltham, MA, USA). Luciferase reporter assays were performed by using the DualGlo Luciferase Reporter Assay System (Promega Corp.). Firefly luciferase light output was normalized by Renilla luciferase output after subtraction of background light output by Victor 3 (PerkinElmer).

\section{Immunohistochemistry for Seladin-1/DHCR24}

Sections (4- $\mu \mathrm{m}$ thick) were obtained from formalin-fixed and paraffin-embedded radical prostatectomy specimens. The sections were deparaffinized in Bio-Clear (Bio-Optica, Milan, Italy) and hydrated with graded ethanol. To block endogenous peroxidase activity, slides were treated with $3.0 \%$ hydrogen peroxidase in distilled water for $10 \mathrm{~min}$. Antigen retrieval was routinely performed by immersing the sections in EDTA buffer $\mathrm{pH} 8.0$ in thermostatate bath (DAKO A/S, Glostrup, Denmark) at $98^{\circ} \mathrm{C}$ for $30 \mathrm{~min}$. Then the tissue sections were stained with a polyclonal antibody against seladin-1/DHCR24 ${ }^{9}$ at 1:50 dilution and incubated for $2 \mathrm{~h}$ at room temperature. Primary antibody bound to antigen was detected with a standard streptavidin-biotin-peroxidase technique (LabVision, Fremont, CA, USA) and visualized with 3,3'-diaminobenzidine (BioGenex, San Ramon, CA, USA) as chromogen. Nuclei were counterstained with Mayer's hematoxylin. Sections of strongly positive adrenal cortical adenoma were used as positive controls whereas negative controls were performed by replacing the primary antibody with a nonimmune serum at the same concentration.

\section{Cholesterol Measurement}

The amount of cholesterol was determined by gas chromatography-mass spectrometry (GC/MS) using stigmasterol as internal standard. Cells were harvested and homogenized as previously described. ${ }^{24}$ The protein concentration was determined by using the Bradford method. Proteins $(5 \mu \mathrm{g})$ were used for cholesterol determination. After the addition of stigmasterol (1000 ng), sterols were saponified in $1 \mathrm{~N} \mathrm{NaOH}$ in $\mathrm{MeOH}$ at $40^{\circ} \mathrm{C}$ for $60 \mathrm{~min}$ and successively extracted with $n$-hexane. After evaporation, sterols were derivatized in $\mathrm{N}, \mathrm{O}$ bis(trimethylsilyl)-trifluoroacetamide (BSTFA) with $10 \%$ trimethyl-chlorosilane at $70^{\circ} \mathrm{C}$ for $30 \mathrm{~min}$. BSTFA solution $(2 \mu \mathrm{l})$ was automatically injected for analysis. Calibration curve of cholesterol (range 50-2000 ng) with $1000 \mathrm{ng}$ of stigmasterol as internal standard was used for cholesterol quantification. Each point was obtained by adding the appropriate quantities of cholesterol and internal standard and performing the same procedure of the samples. The experimental conditions for the samples analysis were as previously reported. $^{24}$

\section{Statistical Analysis}

Statistical analysis was performed using the Statistical Package for the Social Sciences software (SPSS, Evanston, IL, USA). Statistical analysis of cell lines data was performed by $t$-test. The clinical and pathologic variables were explored for the associations with seladin-1/DHCR24 levels. Owing to nonparametric distribution, Mann-Whitney $U$-test and Wilcoxon's rank sum text for unpaired data were performed and correlation between two variables was ascertained by Spearman's correlation test. $P$-value $<0.05$ was considered statistically significant. Results were expressed as median or mean \pm s.e. unless otherwise stated.

\section{RESULTS}

\section{Androgen-Responsiveness of ARE Sequences in Seladin-1/} DHCR24 Promoter Region

We first focused on the functional activity of seladin-1/ DHCR24 ARE sequences by a luciferase reporter gene system.

When CHO cells were transiently transfected with selaprom-tataluc plasmid and pSVAR0 expression plasmid, and treated with the AR-agonist R1881 (10 nM), the luciferase activity of the cells showed a threefold increase compared to the basal level. The ARE-dependent transactivation by R1881 determined a marked increase (fivefold) of luciferase activity also in BPH cells (Figure 1).

\section{Seladin-1/DHCR24 Expression in Prostate Cells and Correlation with Cell Cholesterol Amount}

In order to investigate the androgen responsiveness of seladin-1/DHCR24 in prostate cell models, we measured the expression level of this gene by quantitative real-time RT-PCR (qRT-PCR) in the AR-positive CaP cell line DU145-AR ${ }^{18}$ and in BPH cells ${ }^{22}$ expressing endogenous AR. Treatment with R1881 (10 nM, 24h) induced a 5- and

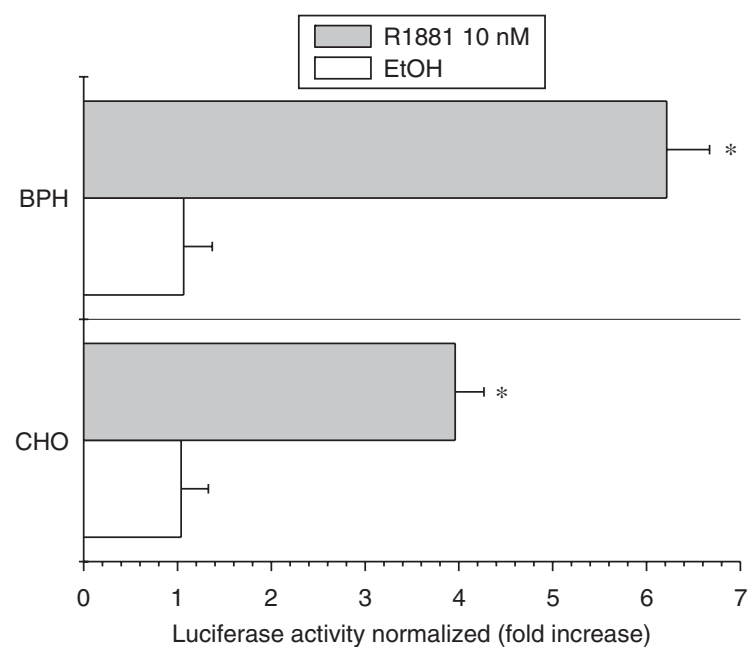

Figure 1 Functional analysis of seladin-1/DHCR24 ARE. CHO cells and human benign prostate hyperplasia (BPH) cells were transfected with selaprom-tataluc construct, pSVARO expression plasmid and pGL 4.75. Cells were treated with ethanol vehicle (EtOH) or R1881 (10 nM, 24h). Firefly luciferase light output was normalized by Renilla luciferase output. Measurements, reported as fold increase vs vehicle, represent the mean \pm s.e. of three independent experiments. Statistical analysis was performed by $t$-test; ${ }^{\star} P<0.05$ vs vehicle. 
2.5 -fold increase of seladin-1/DHCR24 expression vs untreated cells, respectively (Figure 2a). To further evaluate the involvement of AR in modulating seladin-1/DHCR24 expression and to assess the presence of a correlation with cell cholesterol content, we measured both the gene expression level by qRT-PCR and the cell cholesterol amount by GC/MS in CaP cell lines. We used AR-negative, ie DU145-Mock, PC3-wt and PC3-Neo, and AR-positive CaP cells, ie LNCaP, DU145-AR and PC3-AR. The highly invasive AR-negative cells were characterized by a lower expression of seladin-1/ DHCR24 with respect to the AR-positive CaP cells (Figure 2b). Moreover, this different expression was paralleled by a modification of cholesterol content. In fact, in DU145-Mock total cholesterol was significantly lower compared to LNCaP cells $(9.58 \pm 0.75$ vs $33.06 \pm 3.78 \mathrm{ng}$, mean \pm s.e., $P<0.01$, $t$-test). These cell lines were selected as representative of cells not expressing or naturally expressing AR. Another cell line
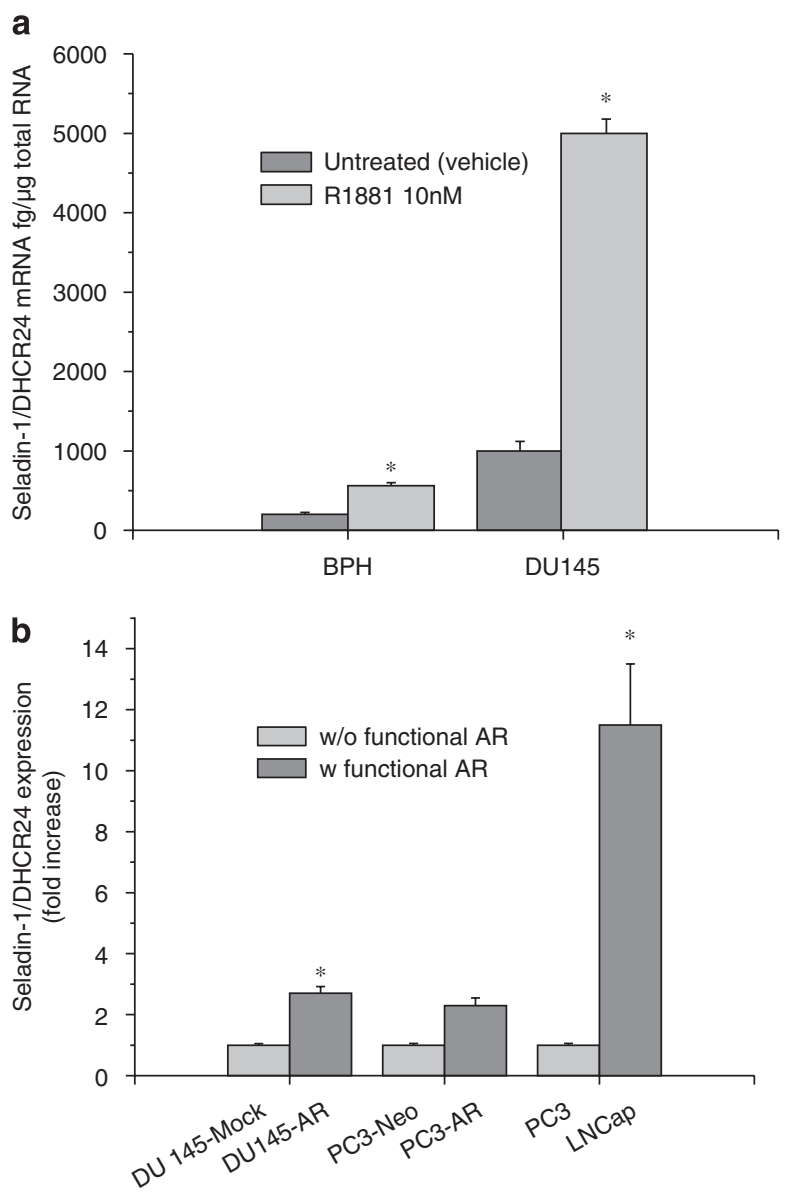

Figure 2 AR regulation of seladin-1/DHCR24 expression in prostate cells. (a) Expression of seladin-1/DHCR24 in DU145-AR and BPH cells in basal conditions and after exposure to R1881. (b) Expression of seladin-1/DHCR24 in different human $\mathrm{CaP}$ cell lines. The amount of mRNA was measured in DU145-Mock, PC3, PC3-Neo cell lines (without functional AR, w/o AR) and in DU145-AR, PC3-AR, LNCaP cells (with functional AR, w AR) and was reported as fold increase of AR-positive vs AR-negative cells, considered as 1. Statistical analysis was performed by $t$-test; ${ }^{\star} P<0.05$ vs control cells. not expressing AR (ie PC3) was used for cholesterol measurement, and in this case the comparison was made between wild-type cells and cells in which AR expression was induced exogenously (PC3-AR). In PC3-AR cells the amount of cell cholesterol was higher than in PC3-Neo $(7.69 \pm 0.10$ vs $6.31 \pm 0.13 \mathrm{ng}$, mean \pm s.e., $P<0.01, t$-test $)$.

\section{Expression of Seladin-1/DHCR24 mRNA and Immunohystochemical Analysis in Human Normal and Tumor Prostate Tissues}

Until now, no data about the expression of seladin-1/ DHCR24 in CaP tissues vs paired normal tissues are available. The amount of mRNA for seladin-1/DHCR24 was investigated in tumor specimens derived from patients who underwent radical prostatectomy for clinically localized CaP. By using qRT-PCR we evaluated seladin-1/DHCR24 expression in a cohort of $61 \mathrm{CaP}$ specimens collected consecutively at surgery (Table 1). The amount of seladin-1/DHCR24 mRNA was found to be significantly higher in prostate tumors compared to the adjacent normal tissue. The median expression level in the tumor tissue was $155 \mathrm{fg} / \mu \mathrm{g}$ total RNA as opposed to $57.6 \mathrm{fg} / \mu \mathrm{g}$ total RNA $(P=0.021)$ in the normal specimens. In order to confirm that higher mRNA expression corresponded to increased protein levels and to verify the

Table 1 Clinical and pathologic demographics of 61 men with clinically localized CaP treated by radical prostatectomy

\begin{tabular}{|c|c|c|}
\hline Patients data & Surgery $(n=61)$ & $\begin{array}{l}\text { Biochemical } \\
\text { relapse }\end{array}$ \\
\hline Follow-up $(n=50)$ & $\begin{array}{l}\text { 3-97 months (mean: } \\
48.50 \text { months) }\end{array}$ & $(38 \%) n=19$ \\
\hline Age $(n=54)$ & $\begin{array}{c}\text { 51-78 years (mean: } \\
54.62 \text { years) }\end{array}$ & \\
\hline Gleason score $\leqslant 7$ & $n=46(75 \%)$ & $(24 \%)$ \\
\hline Gleason score $>7$ & $n=15(25 \%)$ & $(60 \%)$ \\
\hline pT2 & $n=33(54 \%)$ & $(25 \%)$ \\
\hline pT3-pT4 & $n=28(46 \%)$ & $(43 \%)$ \\
\hline Lymph node & $n=61$ & \\
\hline Positive & $n=8(13.1 \%)$ & $(75 \%)$ \\
\hline Negative & $n=53(86.9 \%)$ & (26.4\%) \\
\hline Surgical margins & $n=34$ & \\
\hline Positive & $n=6(18 \%)$ & (33.3\%) \\
\hline Negative & $n=28(82 \%)$ & (32.1\%) \\
\hline Bladder invasion & $n=34$ & \\
\hline Positive & $n=3(8.8 \%)$ & $(100 \%)$ \\
\hline Negative & $n=31(91.1 \%)$ & $(25.8 \%)$ \\
\hline
\end{tabular}



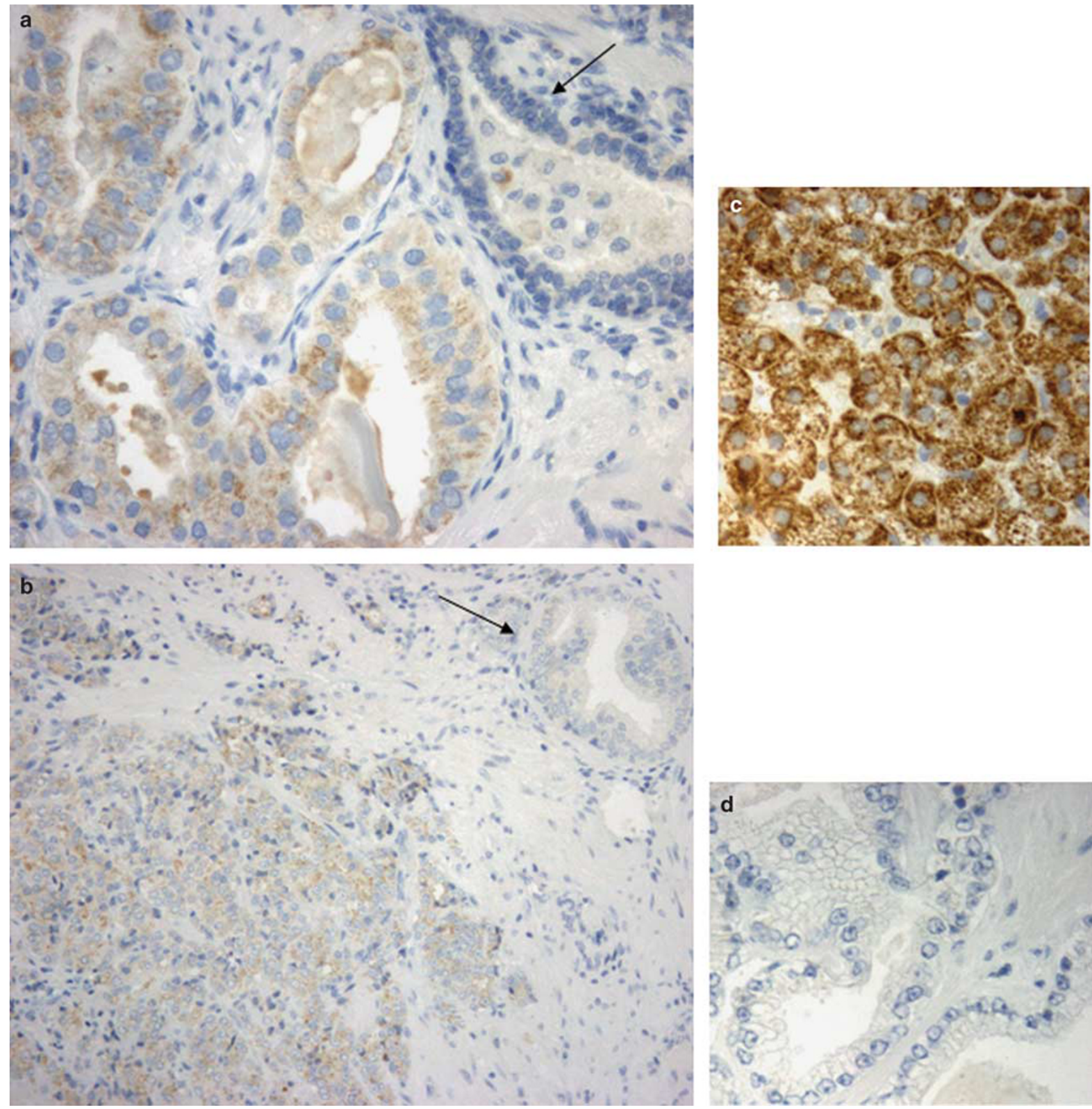

Figure 3 Immunohistochemistry for seladin-1/DHCR24 performed on formalin-fixed and paraffin-embedded CaP specimens at two different original magnifications (a) $\times 100$ and (b) $\times 50$. The arrows indicate areas of normal prostate tissue. (c) Section of human adrenal cortical adenoma, which strongly expresses seladin-1/DHCR24 protein $(\times 150)$. (d) CaP section stained with a nonimmune serum, used as a negative control.

localization of the protein in $\mathrm{CaP}$ sections, immunohystochemistry for seladin-1/DHCR24 was performed on 10 human prostate tissue specimens from our cohort of patients. A representative experiment is shown in Figure 3. Seladin-1/ DHCR24 staining was detected predominantly in the cytoplasm and was expressed only at weak levels within the areas of normal prostate tissue (see arrows in Figure 3a and b), whereas a markedly stronger signal was detected in the cancerous glandular epithelia (Figure $3 \mathrm{a}$ and $\mathrm{b}$ ). Sections of human adrenal cortical adenoma, which expresses high levels of seladin-1/DHCR24, ${ }^{12}$ served as the positive control (Figure 3c). Control experiments by using nonimmune serum gave a negligible signal (Figure 3d). In addition, qRT-PCR showed that the expression of seladin-1/DHCR24 in prostate tumor samples is directly related to the mRNA levels of PSA $(R=0.641, P=0.0001)$, in agreement with the androgenresponsiveness of the gene, as observed in $\mathrm{CaP}$ cell lines (Figure 4). 


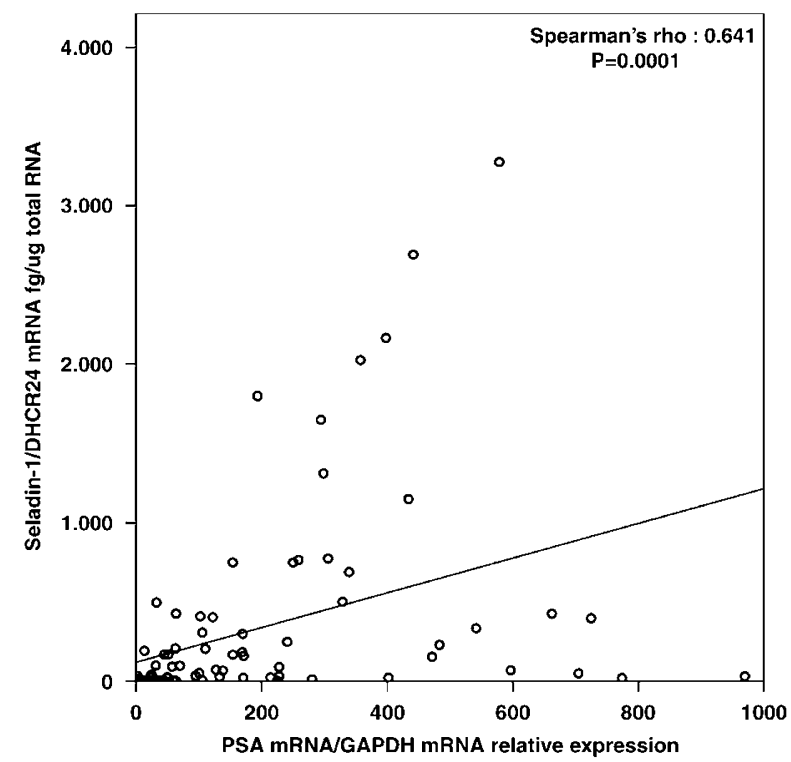

Figure 4 Correlation between the amount of seladin-1/DHCR24 and PSA expression in patients treated by surgery. Statistical analysis was performed by using Spearman's correlation test $(R=0.641 ; P=0.0001)$.

With regard to the clinical parameters of the patients, higher levels of seladin-1/DHCR24 expression were significantly associated with a higher T stage $(P=0.04$; Table 2$)$. A direct correlation between seladin-1/DHCR24 expression and bladder invasion $(P=0.006)$ was also found, although the meaning of this finding is limited by the fact that only 3 out of the 34 analyzed histological samples fell into this category. It has to be said that in patients with locally advanced disease surgery is considered a possible treatment only in very selected cases ${ }^{25,26}$ and therefore the availability of surgical samples is a very rare event.

\section{Seladin-1/DHCR24 Expression in CaP After Androgen Ablation Treatment}

To gain further insight on the androgen-mediated regulation of the seladin-1/DHCR24 gene, we examined the levels of mRNA in CaP specimens of patients treated with androgen deprivation for 3 months before radical prostatectomy $(n=24)$. The amount of seladin-1/DHCR24 expression was significantly lower in this group of patients compared to the 61 patients, who underwent prostatectomy without prior treatment $(P=0.005$; Figure 5$)$.

\section{DISCUSSION}

Seladin-1/DHCR24 is broadly expressed in most peripheral tissues, including the prostate, ${ }^{9}$ and are important in cholesterol biosynthesis by catalyzing the conversion of desmosterol into cholesterol. ${ }^{6}$ Altered levels of expression of this gene have been detected in different neoplastic diseases ${ }^{11-13}$ and reduced expression in $\mathrm{CaP}$ has been associated with an increased metastatic risk. ${ }^{5}$ The androgen-responsiveness of seladin-1/DHCR24 has been hypothesized to be related to an
Table 2 Relationship between seladin-1/DHCR24 expression and clinical features of patients treated by radical prostatectomy

Clinical features Patients treated by surgery $(n=61)$

PSA recurrence
No
Yes
Stage
pT2
pT3-T4

Lymph node
No
Yes

$$
\begin{gathered}
n=58 \\
160.8 \\
282.5 \\
P=0.73 \\
n=61 \\
65.8 \\
239.3 \\
P=0.04 \\
n=61 \\
168 \\
230 \\
P=0.6
\end{gathered}
$$

$\begin{array}{lc}\text { Surgical margin } & n=34 \\ \text { No } & 169 \\ \text { Yes } & 1217.5 \\ & P=0.07 \\ \text { Bladder invasion } & n=34 \\ \text { No } & 170 \\ \text { Yes } & 2691 \\ & P=0.006 \\ \text { Gleason score } & \\ <7 & n=61 \\ 7 & 170 \\ >7 & 92.5 \\ & 28.2 \\ \text { PSA at diagnosis } & P=0.31 \\ <9 & \\ \geqslant 9 & n=38 \\ & 207.5 \\ & 239.3 \\ & P=0.68\end{array}$

PSA, prostate-specific antigen.

The numbers indicate seladin-1/DHCR24 expression (fg mRNA/ $\mu \mathrm{g}$ total RNA, median value). Statistical analysis was performed by Mann-Whitney test and Wilcoxon's rank sum test; $n$ represents the number of CaP patients falling into the indicated clinical features category. Significant values $(P<0.05)$ are in bold font.

ARE identified in the gene promoter region, ${ }^{14}$ even though functional evidence was still lacking, so far. This study investigated the functional activity of seladin-1/DHCR24 


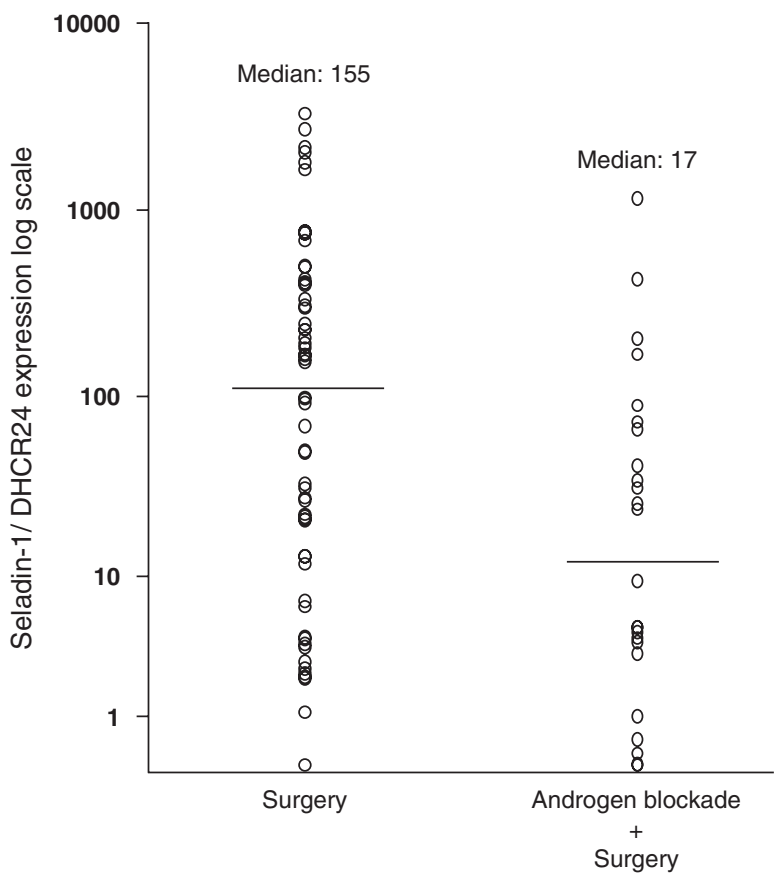

Figure 5 Seladin-1/DHCR24 expression (fg mRNA/ $\mu \mathrm{g}$ total RNA, log scale) evaluated by qRT-PCR in CaP tissues from patients treated by surgery only or from patients treated by androgen ablation before surgery. Statistical analysis was performed by using Mann-Whitney test $(P=0.005)$.

ARE sequences by a luciferase reporter gene assay. The increase of luciferase activity in response to the AR agonist R1881 suggests the presence of a classical AR-mediated mechanism of transcriptional regulation of seladin-1/DHCR24 expression. This finding was confirmed by the increase of the amount of transcript elicited by R1881 in AR-positive CaP and $\mathrm{BPH}$ cells.

In order to investigate the relationship between seladin-1/ DHCR24 expression and its enzymatic activity to produce cholesterol, the expression level of the gene was determined by qRT-PCR and the total cholesterol amount was measured by GC/MS. In AR-positive CaP cells the mRNA level of seladin-1/DHCR24 and the total cholesterol amount were higher compared to AR-negative cells. These results indicated that in CaP cell models the expression of seladin-1/DHCR24 paralleled the cholesterol content and that the presence of a functional AR was associated with higher levels of expression of the gene. It is now clear that the reexpression of the wildtype AR contributes to a more differentiated phenotype in CaP cell lines. ${ }^{19,27}$ We observed increased levels of seladin-1/ DHCR24 expression/activity following AR reexpression in AR-negative CaP cells. From this evidence we can speculate that both the expression and the function of seladin-1/ DHCR24 are modulated by a newly restored androgen responsiveness. According to our findings, it has been demonstrated that a deregulated activation of the AR signalling during progression of $\mathrm{CaP}$ may occur also in a ligand-independent manner, through different mechanisms involving for instance AR activation by growth factors, receptor tyrosine kinases through the MAPK or the AKT pathways, or mutated coregulators. ${ }^{28}$

With regard to the enzymatic activity of seladin-1/ DHCR24, involving the biosynthesis of cholesterol, it can be pointed out the fact that this gene may be involved in the organization of cholesterol-rich detergent-resistant membrane domains (DRMs), namely lipid rafts, as demonstrated by the observation that a reduced protein content has been found in DRMs of seladin-1/DHCR24-deficient mouse brains. ${ }^{7}$ Interestingly, an involvement of lipid rafts in modulating cell signalling has been hypothesized. In particular, expansion of the cholesterol-rich membrane compartment, within certain limits, is likely to promote the formation of raft-resident signalling complexes that promote cell proliferation and survival in tumoral cells, including $\mathrm{CaP}^{29}$

Whereas an association between decreased levels of seladin-1/DHCR24 and metastasis incidence has been found, ${ }^{5}$ no evidence concerning the expression of this gene in $\mathrm{CaP}$ tissues $v s$ adjacent normal tissues was available, so far. Therefore, we evaluated the amount of seladin-1/DHCR24 mRNA in specimens consecutively collected at surgery from a cohort of 61 patients diagnosed for a clinically localized CaP. The amount of transcript was significantly higher in tumoral tissues compared to the adjacent normal tissue. Accordingly, immunohystochemical analysis performed in 10 specimens showed higher protein expression in tumor glands $v s$ adjacent normal areas. The analysis of the correlation between gene expression and clinical-pathological parameters revealed that increased gene expression was significantly associated with a higher $\mathrm{T}$ stage (T3-T4). This bimodal variation of seladin-1/DHCR24 expression (ie increased expression in $\mathrm{CaP}$ and reduced expression in metastatic disease) is in agreement with a similar behavior of a number of anrogen-responsive genes. In their work, Hendriksen et $a l^{5}$ highlighted the fact that the expression of about $50 \%$ of the 200 androgen-responsive genes, which were considered, was upregulated in well-differentiated $\mathrm{CaP}$, whereas the large majority of them was downregulated in metastatic disease, in which the AR pathway is disrupted. These results are in agreement with previous studies, in which gene expression profiling in CaP tissues was performed..$^{30,31}$

Finally, in our study the androgen-mediated expression of seladin-1/DHCR24 was further confirmed in a group of patients subjected to androgen ablation treatment for 3 months before radical prostatectomy. In fact, in these specimens the expression levels of this gene were significantly lower than in patients treated only by surgery. Therefore, seladin-1/DHCR24 may join a list of genes previously shown to be downregulated after androgen deprivation, such as $V E G F^{32}$ and $F G F 8 b^{33}$

In conclusion, in the present study we have shown for the first time that seladin-1/DHCR24 is an androgen-dependent gene regulated by a specific ARE. In addition, the amount of expression in $\mathrm{CaP}$ tissues is higher than in adjacent normal tissues and appears to be associated with a higher $\mathrm{T}$ stage. 
However, further studies designed for instance to overexpress or silence seladin-1/DHCR24 in in vitro models, as well as extensive in vivo studies, are necessary to fully elucidate the involvement of this protein, and therefore of cell lipid content, in modulating the intracellular pathways involved in $\mathrm{CaP}$ progression.

\section{ACKNOWLEDGEMENTS}

This work was supported by grants from Ministero dell'Università e della Ricerca Scientifica (Programmi di Ricerca Scientifica di Rilevante Interesse Nazionale, PRIN2006, coordinators Professor Alessandro Peri and Doctor Giovanna Danza), Università di Firenze, Ente Cassa di Risparmio di Firenze and Astrazeneca. We thank Dr Clara Crescioli, Dr Benedetta Fibbi and Dr Matteo Morello (University of Florence, Florence, Italy) for technical support, Dr YC Chuan (Department of Molecular Medicine and Surgery, Karolinska Hospital, Stockholm, Sweden) for the generous gift of the PSVARO plasmid, and Professor A Poletti (Department of Endocrinology, University of Milan, Italy) for providing DU145-AR and -Mock cell lines.

1. Jemal A, Siegel R, Ward E, et al. Cancer statistics, CA. CA Cancer J Clin 2006;56:106-130.

2. Potosky AL, Feuer EJ, Levin DL. Impact of screening on incidence and mortality of prostate cancer in the United States. Epidemiol Rev 2001;23:181-186.

3. Tomlins SA, Rhodes DR, Perner $S$, et al. Recurrent fusion of TMPRSS2 and ETS transcription factor genes in prostate cancer. Science 2005;310:644-648.

4. Perner S, Demichelis F, Beroukhim R, et al. TMPRSS2:ERG fusionassociated deletions provide insight into the heterogeneity of prostate cancer. Cancer Res 2006;66:8337-8341.

5. Hendriksen PJ, Dits NF, Kokame K, et al. Evolution of the androgen receptor pathway during progression of prostate cancer. Cancer Res 2006;66:5012-5020.

6. Waterham HR, Koster J, Romeijn GJ, et al. Mutations in the 3betahydroxysterol Delta24-reductase gene cause desmosterolosis, an autosomal recessive disorder of cholesterol biosynthesis. Am J Hum Genet 2001;69:685-694.

7. Crameri A, Biondi $E$, Kuehnle $K$, et al. The role of seladin-1/DHCR24 in cholesterol biosynthesis, APP processing and Abeta generation in vivo. EMBO J 2006;25:432-443.

8. Solomon KR, Freeman MR. Cholesterol and prostate cancer. J Cell Biochem 2004;91:54-69.

9. Greeve I, Hermans-Borgmeyer I, Brellinger C, et al. The human DIMINUTO/DWARF1 homolog seladin-1 confers resistance to Alzheimer's disease-associated neurodegeneration and oxidative stress. J Neurosci 2001;20:7345-7352.

10. Wu C, Miloslavskaya I, Demontis $S$, et al. Regulation of cellular response to oncogenic and oxidative stress by Seladin-1. Nature 2004;432: 640-645.

11. Di Stasi D, Vallacchi V, Campi V, et al. DHCR24 gene expression is upregulated in melanoma metastases and associated to resistance to oxidative stress-induced apoptosis. Int J Cancer 2005;115:224-230.

12. Luciani $P$, Ferruzzi $P$, Arnaldi $G$, et al. Expression of the novel ACTH-responsive gene seladin-1/DHCR24 in the normal adrenal cortex and in adrenocortical adenomas and carcinomas. J Clin Endocrinol Metab 2004;89:1332-1339.

13. Luciani P, Gelmini S, Ferrante E, et al. Expression of the anti-apoptotic gene seladin-1 and octreotide-induced apoptosis in $\mathrm{GH}$-secreting and in non-functioning pituitary adenomas. J Clin Endocrinol Metab 2005;90:6156-6161.
14. Nelson PS, Clegg N, Arnold $\mathrm{H}$, et al. The program of androgenresponsive genes in neoplastic prostate epithelium. PNAS 2002:99:11890-11895.

15. Middleton RG. The management of clinically localized prostate cancer: guidelines from the American Urological Association. CA Cancer J Clin 1996;46:249-253.

16. Bova GS, Fox WM, Epstein Jl. Methods of radical prostatectomy specimen processing: a novel technique for harvesting fresh prostate cancer tissue and review of processing techniques. Mod Pathol 1993;6:201-207.

17. Sobin LH, Wittekind C. International Union Against Cancer (UICC): TNM Classification of Malignant Tumors, 6th edn. Wiley-Liss: New York, 2002.

18. Guerini V, Sau D, Scaccianoce E, et al. The androgen derivative 5alphaandrostane-3beta,17beta-diol inhibits prostate cancer cell migration through activation of the estrogen receptor beta subtype. Cancer Res 2005;65:5445-5453.

19. Bonaccorsi L, Carloni V, Muratori $\mathrm{M}$, et al. Androgen receptor expression in prostate carcinoma cells suppresses alpha6beta4 integrin-mediated invasive phenotype. Endocrinology 2000;141: 3172-3182.

20. Hall JM, McDonnell DP, Korach KS. Allosteric regulation of estrogen receptor structure, function, and coactivator recruitment by different estrogen response elements. Mol Endocrinol 2002;16:469-486.

21. Jenster $G$, Spencer TE, Burcin MM, et al. Steroid receptor induction of gene transcription: a two-step model. PNAS 1997;94:7879-7884.

22. Crescioli $C$, Ferruzzi $P$, Caporali $A$, et al. Inhibition of prostate cell growth by BXL-628, a calcitriol analogue selected for a phase II clinical trial in patients with benign prostate hyperplasia. Eur J Endocrinol 2004;150:591-603.

23. Brinkmann AO, Faber PW, van Rooij $\mathrm{HC}$, et al. The human androgen receptor: domain structure, genomic organization and regulation of expression. J Steroid Biochem 1989;34:307-310.

24. Benvenuti S, Saccardi R, Luciani $P$, et al. Neuronal differentiation of human mesenchymal stem cells: changes in the expression of the Alzheimer's disease-related gene seladin-1. Exp Cell Res 2006:312:2592-2604.

25. Heidenreich A, Aus G, Bolla $M$, et al. EAU guidelines on prostate cancer. Eur Urol 2008:53:68-80.

26. Horwich A, Parker C, Kataja V. ESMO Guidelines Working Group. Prostate cancer: ESMO clinical recommendations for diagnosis, treatment and follow-up. Ann Oncol 2008;19(Suppl 2):ii45-ii46.

27. Cinar B, Koeneman KS, Edlund $M$, et al. Androgen receptor mediates the reduced tumor growth, enhanced androgen responsiveness, and selected target gene transactivation in a human prostate cancer cell line. Cancer Res 2001:61:7310-7317.

28. Feldman BJ, Feldman D. The development of androgen independent prostate cancer. Nat Rev Cancer 2001;1:34-35.

29. Freeman MR, Cinar B, Kim J, et al. Transit of hormonal and EGF receptor-dependent signals through cholesterol-rich membranes. Steroids 2007;72:210-217.

30. Lapointe J, Li C, Higgins JP, et al. Gene expression profiling identifies clinically relevant subtypes of prostate cancer. Proc Natl Acad Sci USA 2004;101:811-816.

31. Henshall SM, Afar DE, Hiller J, et al. Survival analysis of genome-wide gene expression profiles of prostate cancers identifies new prognostic targets of disease relapse. Cancer Res 2003;63:4196-4203.

32. Benjamin LE, Golijanin D, Itin A, et al. Selective ablation of immature blood vessels in established human tumors follows vascular endothelial growth factor withdrawal. J Clin Invest 1999;103: 159-165.

33. Gnanapragasam VJ, Robson CN, Neal DE, et al. Regulation of FGF8 expression by the androgen receptor in human prostate cancer. Oncogene 2002;21:5069-5080. 